\title{
Prevalence and Factors Associated with Burnout Syndrome among Resident Doctors at Tertiary Teaching Hospitals in Dar es Salaam, Tanzania
}

\author{
Edwin Rwebugisa Lugazia ${ }^{1,2}$, Happiness Charles Sway', Respicious Lwezimula Boniface ${ }^{1,3,4^{*} \text {, }}$ \\ Asha Abdullah ${ }^{1,3}$
}

\author{
${ }^{1}$ Muhimbili University of Health and Allied Sciences (MUHAS), Dar es Salaam, Tanzania \\ ${ }^{2}$ Jakaya Kikwete Cardiac Institute, Dar es Salaam, Tanzania \\ ${ }^{3}$ Muhimbili Orthopaedic Institute (MOI), Dar es Salaam, Tanzania \\ ${ }^{4}$ Injury Control Centre Tanzania (ICCT), Dar es Salaam, Tanzania \\ Email: ^respiciousboniface@gmail.com
}

How to cite this paper: Lugazia, E.R., Sway, H.C., Boniface, R.L. and Abdullah, A. (2022) Prevalence and Factors Associated with Burnout Syndrome among Resident Doctors at Tertiary Teaching Hospitals in Dar es Salaam, Tanzania. International Journal of Clinical Medicine, 13, 36-49. https://doi.org/10.4236/ijcm.2022.131003

Received: December 6, 2021

Accepted: January 11, 2022

Published: January 14, 2022

Copyright $\odot 2022$ by author(s) and Scientific Research Publishing Inc. This work is licensed under the Creative Commons Attribution International License (CC BY 4.0).

http://creativecommons.org/licenses/by/4.0/

(c) (i) Open Access

\begin{abstract}
Introduction: Burnout syndrome is prevalent to a great extent among medical residents, and this can interfere with their training and patient management. However, the extent of the problem is still unknown in our setting. This study therefore aimed at determining prevalence and factors associated with burnout syndrome among resident doctors at tertiary teaching hospitals in Dar es Salaam, Tanzania. Method: A cross-sectional study of resident doctors was carried out in four teaching hospitals of Muhimbili University of Health and Allied Sciences between January 2021 and March 2021. Participants were interviewed using a structured questionnaire and Maslach Burnout Inventory. Results: The study had 398 participants with a mean age of $35 \pm 3.5$ years. Overall burnout prevalence was $33.7 \%$, as for the burnout dimensions, 205 (51.5\%) respondents reported burnout in the dimension of emotional exhaustion (EE), 177 (44.5\%) in the dimension of depersonalization (D), and $144(36.2 \%)$ in the dimension of reduced personal accomplishment (RPA). Independent factors associated with burnout syndrome were: inadequate support from residency program supervisors (Odds Ratio (OR) 1.97, 95\% CI: 1.23 - 3.14, p = 0.005), work-related family conflicts (Odds Ratio (OR) 3.2, 95\% CI: $1.35-7.71, \mathrm{p}=0.008$ ), stressful call perception (Odds Ratio (OR) 3.31, 95\% CI: $1.90-5.76, \mathrm{p}=0.001$ ) and each added year of study (Odds Ratio (OR) 3.46, 95\% CI: $1.08-6.73, \mathrm{p}=0.009$ ). Conclusion: Burnout is a problem among resident doctors in Tanzania. This could be addressed by directing preventive and intervention measures in the residency training pro-
\end{abstract}


gram. Periodic assessment is also needed to mitigate factors associated with burnout among resident doctors.

\section{Keywords}

Burnout, Resident Doctors, Emotional Exhaustion (EE), Depersonalization (DP), Reduced Personal Accomplishment (RPA)

\section{Introduction}

Burnout is a state of physical, mental, and emotional exhaustion arising from a continued response to chronic interpersonal stressors while at work, which in turn affects the working efficiency of a person [1]. The term was first introduced by Freudeberger and Maslach who independently studied the social issues faced by underprivileged citizens in 1970, and in 1974 it was described among health care professionals [2]. Burnout syndrome among health care professionals has become a serious health problem and the mental health of doctors is an issue of growing concern all over the world as it frequently interferes with their professional training and responsibilities [3]. Among practicing physicians, it has reached epidemic levels with a prevalence that approximates 50\% [4]. The condition is also well associated with negative physiological, cognitive, psychological, and behavioral manifestations which create severe pressure on the whole health care system threatening patients' care and safety. It is not a sign of weakness, mental illness, or inability to cope with life and it can be treated, and prevented [5].

Burnout appears to be quite prevalent in both developing and developed countries and probably represents considerable economic, social and psychological costs to employees and employers in these countries. The problem of residents' burnout is widely recognized with diverse solutions implemented across developed countries. However, there is a lack of clarity about the global prevalence of burnout among medical residents due to limited evidence on residents' burnout in low-income and middle-income countries (LMIC). This affects interventions to prevent and reduce residents' burnout as most of the studies of sufficient quality have only been done in high-income countries [6].

Although the factors that contribute to residents' burnout are unclear, several studies have explored possible reasons for burnout in residency training. In these studies, residents report that time demands, workload, practice setting, lack of control over time management, work planning, work organization, specialty choice, inherently difficult job situations, sleep deprivation, problems with work-life balance and interpersonal relationships are stressors that may contribute to burnout [7] [8].

Other factors cited in the literature include age, gender, marital status and parenting responsibilities. Concerning gender, the previous speculation had led to 
the hypothesis that women residents are more prone to stress and be at a greater risk of burnout as a result of conflicts between traditional gender roles and professional practice and because of the climate of medical education which is competitive and oriented towards masculine tradition [9]. These stressors have resulted in reported incidence of psychological symptoms with feelings of becoming less humanistic, more cynical and "burning out" during residency training [10]. While previous studies done elsewhere have focused on identifying stress factors as perceived by resident doctors [11], there is insufficient information on burnout among doctors in residency training in our country. This study was therefore conducted to help us understand the prevalence and factors associated with burnout syndrome among resident doctors at Tertiary Teaching Hospitals in Dar es Salaam, Tanzania.

\section{Methodology}

Study setting. Data were collected from four University teaching hospitals located in Ilala district of Dar es Salaam, Tanzania. Involved hospitals were; Muhimbili National Hospital (MNH), Muhimbili Orthopaedics Institute (MOI), Jakaya Kikwete Cardiac Institute (JKCI) and Ocean Road Cancer Institute (ORCI) where the Muhimbili University of Health and Allied Sciences resident doctors do their clinical rotations.

Muhimbili National Hospital, is a national referral hospital with a bed capacity of 1500 beds, attending 1000 to 1200 outpatients per day, and 1000 to 1200 inpatients per week. Muhimbili Orthopaedics Institute, is a national specialized hospital offering Orthopedic and Neurosurgical care with a bed capacity of 362 beds, attending on average 4000 outpatients and 700 inpatients per week.

Jakaya Kikwete Cardiac Institute, is a national specialized hospital offering cardiovascular care. The Institute has 103 bed capacity attending on average 700 outpatients and 100 inpatients per week.

Ocean Road Cancer Institute, is a national specialized hospital in cancer treatment and care with a bed capacity of 270 beds attending on average 1800 outpatients and 150 inpatients per week.

Study Design. A prospective cross-sectional study was conducted.

Study population. The study population comprised of Muhimbili University of Health and Allied Sciences resident doctors (first to third year), doing clinical rotations in 4 involved teaching hospitals between January 2021 and March 2021.

Sample size. Assumptions made in determining the sample size were: prevalence of burnout syndrome among resident doctors is 55\% [12], precision of 5\% and confidence level of 95\%. Formula for sample size calculation [13],

$$
N=Z^{2} P(1-P) / e^{2} .
$$

$(N=$ Sample size; $Z$ at $95 \%$ confidence level $(\mathrm{p}=0.05)=1.96 ; P=$ prevalence; $e=$ precision level). 


$$
N=1.96^{2} \times 0.55(1-0.55) / 0.05^{2}=380,
$$

Taking a non-response rate of $10 \%$ into consideration, the corrected sample size was 420 .

Sampling. All residents were grouped according to their specialties of training. The number selected in each department was obtained by the proportional sampling method. Enrollment was done after proper explanation to the residents about the study aim and written informed consent was obtained. The inclusion criteria were resident doctors who consented to participate.

Data collection and management. Data were collected using a structured self-administered questionnaire designed by principal investigator. It comprised of two sections, section one which consisted of socio-demographic characteristics and relevant work-related characteristics (including specialty, year of study, number of working hours per day, number of night calls per month, working relationship with colleagues, average night's sleep hours, support from supervisors, work-related family conflict, work autonomy, call perception, years of experience, sponsorship, and remuneration). Section two comprised of an adapted Maslach Burnout Inventory-Human Services Survey (MBI-HSS) designed to measure the presence of burnout (Appendix). A pilot study was conducted to ensure validity and reliability of the data collection tool. Direct scoring was used for the items in each subscale (emotional exhaustion, depersonalization and personal accomplishments) by adding together the values of the ratings. A high degree of burnout is represented by high score of emotional exhaustion (score of $\geq 27$ ) and depersonalization (score of $\geq 13$ ) and a low score of personal accomplishments (score of $\leq 33$ ). To determine the prevalence of burnout syndrome amongst resident doctors in this study, we used the tridimensional diagnosis criteria for Burnout Syndrome using Maslach Burnout Inventory (emotional exhaustion, depersonalization and personal accomplishment). Accordingly, those who scored high on both emotional exhaustion (score of $\geq 27$ ) and depersonalization (score of $\geq 13$ ) plus low personal accomplishment domains (score of $\leq 33$ ), were considered to have burnout. Data were double-entered into Excel (Microsoft $\hat{A}^{\oplus}$ Excel, Seattle Washington), Statistical analysis was conducted using Statistical Package for Social Sciences (SPSS) version 23 (IBM Corp. IBM SPSS Statistics for Windows [Internet]. Armonk, NY: IBM Corp; 2017).

Data analysis. All variables were categorized and described using frequency distribution. Chi-square test was used for bivariate analysis and those variables with observed frequency less than five Fisher's exact test was applied. A variable with ( $p \leq 0.05)$ burnout was considered to be statistically significant. Variables that demonstrated significant bivariate association with burnout were entered into the multivariate logistic regression modal to assess independent effects. $\mathrm{Pa}$ rameter of measurement to assess association was odds ratio.

Ethical consideration. Ethical approval for the study was obtained from the Muhimbili University of Health and Allied Sciences Research Ethics Committee. An informed written consent was sought from participants. 


\section{Results}

A total of 420 residents were enrolled in our study, from which 406 (96.6\%) responded. Eight (2\%) were excluded due to incomplete data. Data from 398 residents were analyzed (Figure 1).

\subsection{Socio-Demographic and Work-Related Characteristics of the Participants}

The participants' age ranged between 24 and 50 years with a mean age of $35 \pm$ 3.5 years. Majorities 243/398 (61.1\%) were males, 256/398 (64.3\%) were married, and $256 / 398$ (64.3\%) had children. Three hundred and twenty-five $(81.7 \%)$ had employment, and $277 / 398$ (69.6\%) of the residents were living outside the university campus. One hundred and fifty-nine (39.9\%) residents were in their first year of training, and 100/398 (25.1\%) were in their third year of training. Majorities $284 / 398$ (71.4\%) had sponsorship for their studies, 341/398 (85.7\%) reported inadequate night sleep hours, 208/398 (52\%) reported inadequate remuneration and over half $256 / 398$ (64.3\%) reported working more than $>9$ hours per day. Two hundred and six (65.8\%) of residents perceived call duty as stressful, and 167/398 (42\%) reported inadequate support from their supervisors (Table 1).

\subsection{Prevalence of Burnout}

Out of 398 residents involved in this study, burnout syndrome accounted for 134/398 (33.7\%) of participants (Figure 2).

\subsection{Prevalence of Burnout across Dimensions among Participants}

Analyzing each sub-scale separately according to Maslach's categorization, 205/398

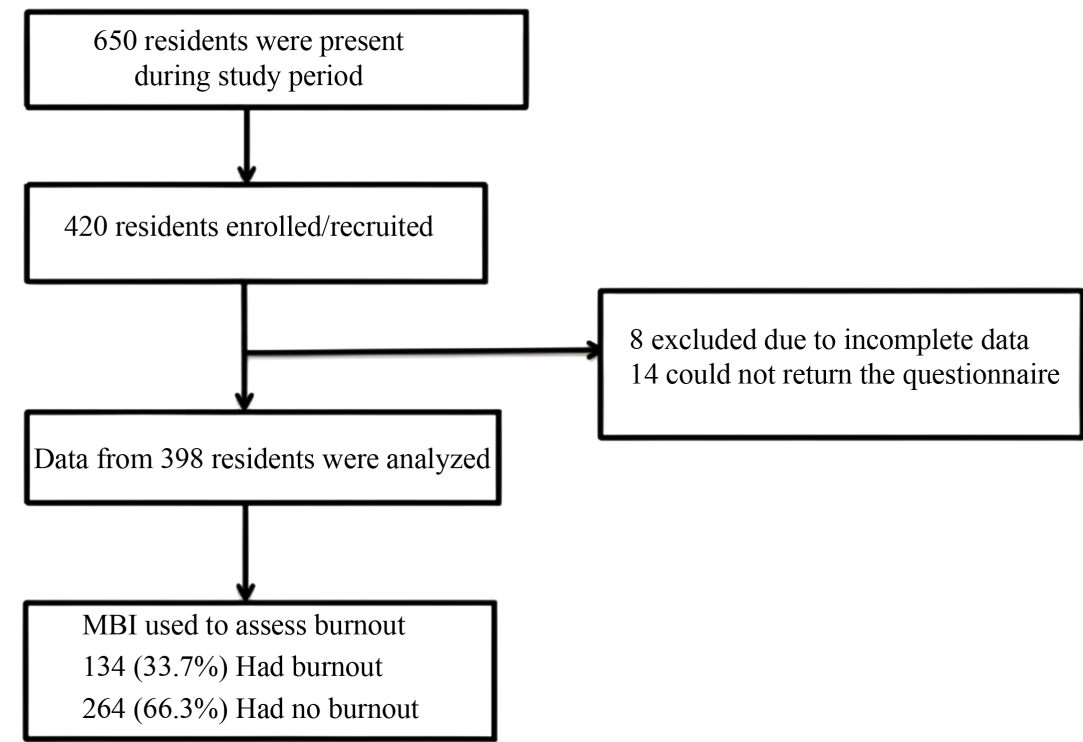

Figure 1. Schematic of residents' enrolment. 


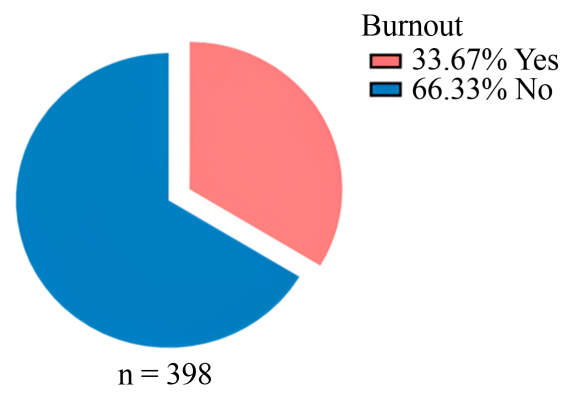

Figure 2. Proportional of residents with burnout.

Table 1. Socio-demographic and work-related characteristics of the participants.

\begin{tabular}{|c|c|c|c|c|c|c|c|}
\hline Variable & Category & $\begin{array}{l}\text { Frequency } \\
\text { (n) }\end{array}$ & $\begin{array}{c}\text { Percent } \\
(\%)\end{array}$ & Variable & Category & Frequency & Percent \\
\hline \multirow{3}{*}{$\begin{array}{l}\text { Age group } \\
\text { (years) }\end{array}$} & $<35$ & 302 & 75.9 & \multirow{3}{*}{$\begin{array}{l}\text { Year of } \\
\text { residency }\end{array}$} & $1^{\text {st }}$ year & 159 & 39.9 \\
\hline & \multirow{2}{*}{$>35$} & \multirow{2}{*}{96} & \multirow{2}{*}{24.1} & & $2^{\text {nd }}$ year & 139 & 34.9 \\
\hline & & & & & $3^{\text {rd }}$ year & 100 & 25.1 \\
\hline \multirow{2}{*}{ Gender } & Male & 243 & 61.1 & \multirow{2}{*}{ Sponsorship } & Sponsored & 284 & 71.4 \\
\hline & Female & 155 & 38.9 & & Not Sponsored & 114 & 28.6 \\
\hline \multirow{2}{*}{ Marital status } & Married & 256 & 64.3 & \multirow{2}{*}{$\begin{array}{c}\text { Night } \\
\text { sleep hours }\end{array}$} & Adequate & 57 & 14.3 \\
\hline & Single & 146 & 35.7 & & Inadequate & 341 & 85.7 \\
\hline \multirow{2}{*}{$\begin{array}{l}\text { Having } \\
\text { Children }\end{array}$} & Yes & 256 & 64.3 & \multirow{2}{*}{$\begin{array}{l}\text { Number of night } \\
\text { shifts per month }\end{array}$} & $<5$ calls & 234 & 58.8 \\
\hline & No & 142 & 35.7 & & $5-10$ calls & 121 & 30.4 \\
\hline \multirow{3}{*}{$\begin{array}{l}\text { Employment } \\
\text { status }\end{array}$} & Employed & 325 & 81.7 & \multirow{2}{*}{ Call perception } & Stressful & 206 & 65.8 \\
\hline & Not Employed & 73 & 18.3 & & Not stressful & 136 & 34.2 \\
\hline & Yes & 16 & 4 & & Adequate & 66 & 16.6 \\
\hline \multirow[t]{2}{*}{ Smoking } & \multirow{2}{*}{ No } & \multirow{2}{*}{382} & \multirow{2}{*}{96} & Remuneration & Not adequate & 208 & 52.3 \\
\hline & & & & & No renumeration & 124 & 31.2 \\
\hline \multirow{3}{*}{ Alcohol use } & Yes & 112 & 28.1 & \multirow{3}{*}{$\begin{array}{l}\text { Support from } \\
\text { supervisors }\end{array}$} & Adequate & 222 & 55.8 \\
\hline & NT & 206 & 710 & & Not adequate & 167 & 42 \\
\hline & 1vo & 200 & 11.9 & & No support & 9 & 2.3 \\
\hline \multirow{3}{*}{ Exercise } & Yes & 260 & 65.3 & & $<5$ & 163 & 41.0 \\
\hline & \multirow{2}{*}{ No } & \multirow{2}{*}{138} & \multirow{2}{*}{34.7} & $\begin{array}{c}\text { Years } \\
\text { of experience }\end{array}$ & $5-10$ & 194 & 48.7 \\
\hline & & & & & $>10$ & 41 & 10.3 \\
\hline \multirow{2}{*}{$\begin{array}{l}\text { Chronic } \\
\text { disease }\end{array}$} & Yes & 30 & 7.5 & & & & \\
\hline & No & 368 & 92.5 & & & & \\
\hline \multirow[b]{2}{*}{ Accommodation } & At University hostels & 121 & 30.4 & & & & \\
\hline & $\begin{array}{c}\text { Outside } \\
\text { University hostels }\end{array}$ & 277 & 69.6 & & & & \\
\hline
\end{tabular}


(51.5\%) residents reported burnout in the dimension of emotional exhaustion, $177 / 398(44.5 \%)$ in the dimension of depersonalization, and 144/398 (36.2\%) in the dimension of reduced personal accomplishment.

\subsection{Factors Associated with Burnout Syndrome}

The following factors were significantly associated with burnout syndrome after bivariate analysis: Third year of study accounted for majority (47\%) of residents with burnout syndrome compared to first- and second-year residents ( $p$-value $0.001)$, burnout syndrome was more $(38.3 \%)$ among those who reported little work autonomy compared to those who reported much work autonomy (p-value 0.023). Majorities (59.2\%) of those with high work-related family conflict had burnout syndrome compared to those with low and none work-related family conflict ( $\mathrm{p}$-value $<0.001$ ). Those who perceived call duty as stressful had more burnout syndrome $(43.1 \%)$ compared to those who perceived call duty as not stressful (p-value $<0.001$ ), and those with inadequate supervisor's support had more burnout syndrome $(46.7 \%)$ compared to those with adequate support (p-value < 0.001) (Table 2).

The following factors remained statistically significant after multivariate logistic regression analysis: Residents who perceived call duty as stressful were found to be 3.3 times more likely to develop burnout compared to those who perceived it as not stressful. Burnout was about twice as prevalent in residents who reported inadequate support from their residency program supervisors compared to those who reported adequate support. Burnout was 3.2 times more frequent in those who reported having high home work-related conflicts compared to those who reported none conflict. Those in their third of study were 3.4 times more likely to develop burnout compared to those who were in first year of study (Table 2).

\section{Discussion}

This study examined the prevalence and factors associated with burnout syndrome among resident doctors at tertiary teaching hospitals in Dar es Salaam, Tanzania. It revealed the prevalence of $33.7 \%$, which is within the range of burnout syndrome among health care workers reported globally $25 \%$ - 75\% [14]. It is also within the range reported in a systematic review done in Nigeria $23.6 \%$ $51.7 \%$ [15]. Our findings are also similar to a meta-analysis study results done in Brazil in which they reported overall prevalence of $35.7 \%$ [16].

Although the prevalence reported in this study is almost similar to what has been reported in other studies done elsewhere, the implication on health services delivery in Tanzania may be more serious taking into account that, resident doctors form the major part of health care delivery across tertiary hospitals in the country due to low doctor to patient ratio situation facing the country. So, there is a risk of negative impact of burnout on patient care including medical errors, patient safety risks, and potential compromise of quality of care. For 
Table 2. Factors associated with burnout syndrome.

\begin{tabular}{|c|c|c|c|c|c|}
\hline \multicolumn{6}{|c|}{ Burn Out } \\
\hline Factor & Yes n (\%) & No $n(\%)$ & P-Value & $\begin{array}{l}\text { Multivariate } \\
\text { OR (95\% CI) }\end{array}$ & P-Value \\
\hline \multicolumn{6}{|l|}{ Year of Study } \\
\hline First year & $39(24.5)$ & $120(75.5)$ & \multirow{3}{*}{0.001} & 1 & \\
\hline Second year & $48(34.5)$ & $91(65.5)$ & & $1.63(0.96-3.52)$ & 0.046 \\
\hline Third year & $47(47.0)$ & $53(53.0)$ & & $3.46(1.08-6.73)$ & 0.009 \\
\hline \multicolumn{6}{|l|}{ Sponsorship } \\
\hline Sponsored & $99(34.9)$ & $185(65.1)$ & \multirow{2}{*}{0.428} & & \\
\hline Not sponsored & $35(30.7)$ & $79(69.3)$ & & & \\
\hline \multicolumn{6}{|l|}{ Autonomy } \\
\hline Much & $47(27.5)$ & $124(72.5)$ & \multirow{2}{*}{0.023} & 1 & \\
\hline Little & $87(38.3)$ & $140(61.7)$ & & $1.20(0.74-1.94)$ & 0.445 \\
\hline \multicolumn{6}{|l|}{ Conflicts } \\
\hline None & $23(20.9)$ & $87(79.1)$ & \multirow{3}{*}{$<0.001$} & 1 & \\
\hline Low & $89(35.5)$ & $162(64.5)$ & & $1.41(0.77-2.56)$ & 0.064 \\
\hline High & $22(59.5)$ & $15(40.5)$ & & $3.23(1.35-7.71)$ & 0.008 \\
\hline \multicolumn{6}{|l|}{ Night shift (Calls) } \\
\hline$<5$ & $76(32.5)$ & $158(67.5)$ & \multirow{3}{*}{0.592} & & \\
\hline $5-10$ & $45(37.2)$ & $76(62.8)$ & & & \\
\hline$>10$ & $13(30.2)$ & $30(69.8)$ & & & \\
\hline \multicolumn{6}{|l|}{ Call perception } \\
\hline Not Stressful & $21(15.4)$ & $115(84.6)$ & \multirow{2}{*}{$<0.001$} & 1 & \\
\hline Stressful & $113(43.1)$ & $149(56.9)$ & & $3.31(1.90-5.76)$ & 0.001 \\
\hline \multicolumn{6}{|l|}{ Renumeration } \\
\hline Adequate & $17(25.8)$ & $49(74.2)$ & \multirow{3}{*}{0.283} & & \\
\hline Not adequate & $71(34.1)$ & $137(65.9)$ & & & \\
\hline No remuneration & $46(37.1)$ & $78(62.9)$ & & & \\
\hline \multicolumn{6}{|l|}{ Supervisor's support } \\
\hline Adequate & $54(24.3)$ & $168(75.7)$ & \multirow{3}{*}{$<0.001$} & 1 & \\
\hline Not adequate & $78(46.7)$ & $89(53.3)$ & & $1.97(1.23-3.14)$ & 0.005 \\
\hline No support at all & $2(22.2)$ & $7(77.8)$ & & $0.47(0.09-2.44)$ & 0.056 \\
\hline \multicolumn{6}{|l|}{ Night sleep } \\
\hline Inadequate & $117(34.3)$ & $224(65.7)$ & \multirow{2}{*}{0.507} & & \\
\hline Adequate & $17(29.8)$ & $40(70.2)$ & & & \\
\hline
\end{tabular}




\section{Continued}

Working hours

$\leq 9 \quad 42(29.6) \quad 100(70.4)$

$>92(35.9) \quad 164(64.1)$

0.198

Experience (years)

$\begin{array}{llll}<5 & 49(30.1) & 114(69.9) & \\ 5-10 & 70(36.1) & 124(63.9) & 0.447 \\ >10 & 15(36.6) & 26(63.4) & \end{array}$

resident doctors in training there is a risk of depression, suicidal tendencies, and medical illnesses, hence the need for mental health as well as support services to this important group of doctors.

Positive predictors of burnout among resident doctors revealed in this study included work related family conflict. The residency period is highly loaded with psychological stressors [17] and the addition of work-related family conflict could lead to residents having a higher risk of becoming burned out. This was confirmed in our study by the fact that those who admitted having high workrelated family conflicts were significantly associated with burnout, the same factor has been reported in other studies done elsewhere [18] [19] [20]. Inadequate support from residency program supervisors was also found to be a positive predictor of burnout among resident doctors in this study. Those who reported inadequate support from their supervisors where more likely to have burnout syndrome compared to those who reported adequate support. Other studies conducted elsewhere have reported similar findings [21] [22], in which they revealed work place social support was a major characteristic related to good performance. This is an important modifiable finding and has a greater implication in policy change.

The current study also found that senior residents in their third year of study were more likely to develop burnout, similar findings were reported by Dhusia et al. [21]. The increased experience usually accounts for higher working hours, increased workload and it is a time when they are working on their dissertations in our settings, combining all those, puts much pressure on them and may exacerbate the syndrome. Residents who perceived call duty as stressful in this study were more likely to develop burnout compared to those who perceived it as not stressful. Our results are in line with a systematic review done in Nigeria by Ogunsuji et al. [15], which reported perception of call duty as stressful to be positive predictors of burnout among resident doctors. This can be due to the fact that night calls are associated with heavy workload especially handling emergencies, sleep deprivation and few staffs normally present during night shifts in our hospitals.

There are some key limitations in this study: firstly, the study was conducted at tertiary teaching hospitals in Dar es Salaam region. Therefore, it may be diffi- 
cult to generalize the findings to doctors across the country, and hence it may not reflect what is happening in other centers. Secondly, data collectors not collecting all data and so some are missing. Thirdly, information bias from participants and data collectors may have affected the quality of data.

\section{Conclusions}

The study has shown that burnout is prevalent among resident doctors in our setting and it has illuminated some factors that influenced burnout among resident doctors in residency training. There is therefore a need for directing preventive and intervention measures in the residency training program. Periodic assessment is also needed to mitigate factors associated with burnout among resident doctors.

\section{What Is Known about This Topic?}

- Burnout among medical doctors is a global phenomenon.

- Burnout can hinder optimal healthcare delivery.

- Healthcare providers are in prolonged exposure to job stressors.

\section{What This Study Adds}

- This study provides valuable insight into the burden of burnout syndrome among resident doctors in Tanzania hospitals.

- It also points out the need for support services to resident doctors in Tanzania.

\section{Authors' Contributions}

Edwin Rwebugisa Lugazia, Happiness Charles Sway, Respicious Lwezimula Boniface and Asha Abdullah conceived and designed the study. Happiness Charles Sway undertook the data collection and statistical analysis and wrote the first draft of the manuscript. All authors contributed to the intellectual content and approved the final manuscript.

\section{Acknowledgements}

We are grateful to the management and workers of Muhimbili National Hospital, Muhimbili Orthopaedic Institute, Jakaya Kikwete Cardiac Institute and Ocean Road Cancer Institute for their cooperation. This work was supported by Muhimbili University of Health and Allied Sciences (MUHAS).

\section{Conflicts of Interest}

The authors declare no conflicts of interest regarding the publication of this paper.

\section{References}

[1] Maslach, C. and Leiter, M.P. (2016) Understanding the Burnout Experience: Recent Research and Its Implications for Psychiatry. World Psychiatry, 15, 103-111. https://doi.org/10.1002/wps.20311

[2] Dhusia, A.H., Dhaimade, P.A., Jain, A.A., Shemna, S.S. and Dubey, P.N. (2019) Prevalence of Occupational Burnout among Resident Doctors Working in Public Sector Hospitals in Mumbai. Indian Journal of Community Medicine, 44, 352-356. https://doi.org/10.4103/ijcm.IJCM_78_19 
[3] Rothenberger, D.A. (2017) Physician Burnout and Well-Being: A Systematic Review and Framework for Action. Diseases of the Colon \& Rectum, 60, 567-576. https://doi.org/10.1097/DCR.0000000000000844

[4] Shanafelt, T.D., Hasan, O., Dyrbye, L.N., Sinsky, C., Satele, D., Sloan, J. and West, C.P. (2015) Changes in Burnout and Satisfaction with Work-Life Balance in Physicians and the Neral US Working Population between 2011 and 2014. Mayo Clinic Proceedings, 90, 1600-1613. https://doi.org/10.1016/j.mayocp.2015.08.023

[5] Shanafelt, T. and Sloan, J.A. (2003) The Well-Being of Physicians. The American Journal of Medicine, 114, 513-519. https://doi.org/10.1016/S0002-9343(03)00117-7

[6] West, C.P., Dyrbye, L.N., Erwin, P.J. and Shanafelt, T.D. (2016) Interventions to Prevent and Reduce Physician Burnout: A Systematic Review and Meta-Analysis. The Lancet, 388, 2272-2281. https://doi.org/10.1016/S0140-6736(16)31279-X

[7] Cohen, J.S. and Patten, S. (2005) Well-Being in Residency Training: A Survey Examining Resident Physician Satisfaction both within and outside of Residency Training and Mental Health in Alberta. BMC Medical Education, 5, Article No. 21. https://doi.org/10.1186/1472-6920-5-21

[8] Shanafelt, T.D., Bradley, K.A., Wipf, J.E. and Back, A.L. (2002) Burnout and SelfReported Patient Care in an Internal Medicine Residency Program. Annals of Internal Medicine, 136, 358-367. https://doi.org/10.7326/0003-4819-136-5-200203050-00008

[9] Peeters, M.C.W., de Jonge, J. and Janssen, P.P.M. (2004) Work-Home Interference, Job Stressors, and Employee Health in a Longitudinal Perspective. International Journal of Stress Management, 11, 305-322. https://doi.org/10.1037/1072-5245.11.4.305

[10] Ishak, W.W., Lederer, S., Mandili, C., Nikravesh, R., Seligman, L., Vasa, M., Ogunyemi, D. and Bernstein, C.A. (2009) Burnout during Residency Training: A Literature Review. Journal of Graduate Medical Education, 1, 236-242. https://doi.org/10.4300/JGME-D-09-00054.1

[11] Ndom, R.J.E. and Makanjuola, A. (2004) Perceived Stress Factors among Resident Doctors in a Nigerian Teaching Hospital. West African Journal of Medicine, 23, 232-235. https://doi.org/10.4314/wajm.v23i3.28128

[12] Ogundipe, O.A., Olagunju, A.T., Lasebikan, V.O. and Coker, A.O. (2014) Burnout among Doctors in Residency Training in a Tertiary Hospital. Asian Journal of Psychiatry, 10, 27-32. https://doi.org/10.1016/j.ajp.2014.02.010

[13] Yamane, T. (1967) Statistics; an Introductory Analysis. 2nd Edition, Harper and Row, New York.

[14] Fahrenkopf, A.M., Sectish, T.C., Barger, L.K., et al. (2008) Rates of Medication Errors among Depressed and Burnt-Out Residents: Prospective Cohort Study. BMJ, 336, 488-491. https://doi.org/10.1136/bmj.39469.763218.BE

[15] Ogunsuji, O., Oyabeda, I., Olaopa, O. and Efuntoye, O. (2019) Burnout among Nigerian Doctors. A Systematic Review. The Nigerian Medical Practitioner, 76, 24-29.

[16] Rodrigues, H., Cobucci, R., Oliveira, A., Cabral, J.V., Medeiros, L., Gurgel, K., et al. (2018) Burnout Syndrome among Medical Residents: A Systematic Review and Meta-Analysis. PLoS ONE, 13, e0206840. https://doi.org/10.1371/journal.pone.0206840

[17] Amir, E., Kumari, S., Olivetta, U. and Mansoor, M. (2018) Burnout and Depression among Medical Students at Historically Black Colleges and Universities (HBCU) Hospital System. International Journal of Psychology \& Behavior Analysis, 4, 151. https://doi.org/10.15344/2455-3867/2018/151 
[18] Ringrose, R., et al. (2009) Burnout in Medical Residents: A Questionnaire and Interview Study. Psychology, Health \& Medicine, 14, 476-486.

https://doi.org/10.1080/13548500903012822

[19] Häusler, N.B.M. and Hämmig, O. (2018) Effort-Reward Imbalance, Work-Privacy Conflict, and Burnout among Hospital Employees. Journal of Occupational and Environmental Medicine, 60, e183-e187. https://doi.org/10.1097/JOM.0000000000001287

[20] Kocalevent, R., Pinnschmidt, H., Selch, S., et al. (2020) Burnout is Associated with Work-Family Conflict and Gratification Crisis among German Resident Physicians. BMC Medical Education, 20, Article No. 145.

https://doi.org/10.1186/s12909-020-02061-0

[21] Deschamps, F., Castanon, J. and Laraqui, O. (2018) Professional Risk Factors for Burnout among Medical Residents. Journal of Community Medicine and Health Education, 8, Article No. 596.

[22] Isabel S.R., Laura, C.G. and Maria, M.J. (2021) The Role of Burnout in the Association between Work-Related Factors and Perceived Errors in Clinical Practice among Spanish Residents. International Journal of Environmental Research and Public Health, 18, Article No. 4931. https://doi.org/10.3390/ijerph18094931 


\section{Appendix}

\section{A questionnaire}

Prevalence and Factors Associated with Burnout Syndrome among resident Doctors at Tertiary Teaching Hospitals in Dar es Salaam, Tanzania Serial number:

PART I: Socio-demographic and professional characteristics

1. Age ... (years)

2. Gender

Male Female

3. Marital status

Married Single Widowed Separated

4. Do you have children?

Yes

No

5. Employment status

Employed Not employed.

6. Do you smoke?

Yes No

7. Do you take alcohol?

No Yes

8. Practice of physical exercise

Yes No

9. History of any chronic disease?

Yes No

10. Accommodation status

At MUHAS hostels Outside MUHAS hostels

11. Year of study

$1^{\text {st }}$ year $\quad 2^{\text {nd }}$ year $\quad 3^{\text {rd }}$ year

12. Speciality/Department ...

13. Studies sponsorship

Sponsored (Government/Private) Not sponsored (Self sponsorship)

14. Work related Autonomy?

Little Much

15. Work/studies related family conflicts

High Low None

16. Relationship with co-workers/colleagues

Good Bad

17. Average working hours per day...

18. Average night's sleep hours...

19. Number of days on calls per month

Less than $5 \quad 5-10 \quad$ More than 10

20. How do you perceive call duties?...

Stressful Not stressing

21 . How is your remuneration? 
Adequate Not adequate No remuneration at all.

22. Perception of support from the supervisors

Adequate Not adequate No support at all.

23. Number of years working in the health care profession...

PART II:

\begin{tabular}{cccccccc}
\hline \multicolumn{10}{c}{ MBI-Human Services Survey } \\
How Often & 0 & 1 & 2 & 3 & 4 & 5 & 6 \\
\hline & Never & $\begin{array}{c}\text { A few } \\
\text { times a } \\
\text { year or less }\end{array}$ & $\begin{array}{c}\text { Once a } \\
\text { month } \\
\text { or less }\end{array}$ & $\begin{array}{c}\text { A few } \\
\text { times } \\
\text { a month }\end{array}$ & $\begin{array}{c}\text { Once } \\
\text { a week }\end{array}$ & $\begin{array}{c}\text { A few } \\
\text { times } \\
\text { a week }\end{array}$ & $\begin{array}{c}\text { Every } \\
\text { day }\end{array}$ \\
\hline
\end{tabular}

\section{How Often}

\section{0 - 6 Statements}

1. I feel emotionally drained from my work.

2. I feel used up at the end of the workday.

3. I feel fatigued when I get up in the morning and have to face another day on the job.

4. I can easily understand how many my recipients feel about things.

5. I feel treat some recipients as if they were impersonal objects.

6. Working with people all day is really a strain for me.

7. I deal very effectively with the problems of my recipients.

8. I feel burned out from my work.

9. I feel I'm positively influencing other people's lives through my work.

10. I've become more unsympathetic toward people since I took this job.

11. I worry that this job is hardening me emotionally.

12. I feel very energetic.

13. I feel frustrated by my job.

14. I feel I'm working too hard on the job.

15. I don't really care what happens to some recipients.

16. Working with people directly puts too much stress on me.

17. I can easily create a relaxed atmosphere with my recipients.

18. I feel very happy working closely with my recipients.

19. I have accomplished many worthwhile things in this job.

20. I feel like I'm at the end of my rope.

21. In my work, I deal with emotional problems very calmly. 